\title{
RESPONSABILIDADE EM FACE DE PIQUETE NA JURISPRUDÊNCIA NORTE-AMERICANA
}

\section{RESPONSIBILITY IN THE FACE OF PICKET IN THE NORTH AMERICAN JURISPRUDENCE}

EDILTON MEIRELES

Pós-doutor em Direito pela Faculdade de Direito da Universidade de Lisboa. Doutor em Direito pela Pontifícia Universidade Católica de São Paulo (PUC/SP). Professor de Direito Processual Civil na Universidade Federal da Bahia (UFBa). Professor de Direito na Universidade Católica do Salvador (UCSal). Desembargador do Trabalho na Bahia (TRT 5ª Região).edilton_meireles@uol.com.br

\section{RESUMO}

Neste trabalho tratamos do direito de manifestação em piquetes e da responsabilidade que possa advir desses atos em face da jurisprudência da Suprema Corte dos Estados Unidos da América. A partir da análise das principais decisões da Suprema Corte se pode concluir que, de modo geral, os participantes do piquete não respondem quando agem de forma não ilegal. Está sedimentado, no entanto, o entendimento de que o organizador do piquete responde pelos atos dos participantes. A pesquisa desenvolvida se justifica enquanto estudo comparativo e diante do pouco debate existente no Brasil a respeito do tema. Na pesquisa foi utilizado o método dedutivo, limitada à ciência dogmática do direito, com estudo de casos apreciados pelo judiciário.

PALAVRAS-CHAVES: Responsabilidade; Piquete; Estados Unidos; Suprema Corte; Liberdade De Expressão. 


\begin{abstract}
In this work we deal with the right of demonstration in pickets and the responsibility that may arise from these acts in the face of the jurisprudence of the Supreme Court of the United States of America. From the analysis of the Supreme Court's main decisions it can be concluded that, in general, the picket participants do not respond when they act in a non-illegal way. It is settled, however, the understanding that the picket organizer responds by the acts of the participants. The research developed is justified as a comparative study and in view of the little debate that exists in Brazil regarding the subject. In the research was used the deductive method, limited to the dogmatic science of law, with study of cases appreciated by the judiciary.
\end{abstract}

KEYWORDS: Responsibility; Picket; United States; Supreme Court; Freedom Of Expression.

\title{
INTRODUÇÃO
}

Neste artigo tratamos do entendimento jurisprudencial norte-americano a respeito do direito de manifestação em piquetes e da responsabilidade civil que possa advir desses atos.

Cabe advertir, de logo, que para o direito americano a expressão piquete tanto serve para se referir ao movimento dos trabalhadores com objetivos trabalhistas, como o movimento coletivo com finalidade não-trabalhista. Em nosso vocabulário, em geral, designamos esses movimentos não-trabalhistas como protesto (protest), boicote (boycott) ou bloqueio (blockade/obstruct). Seriam estes, por exemplo, os movimentos de boicote a um determinado produto, o bloqueio de acesso a um determinado local ou o protesto contra determinada ação ou conduta ou comportamento (ex.: protesto contra a aprovação de determinado projeto de lei).

A pesquisa se justifica em face do crescente número de movimentos coletivos de protestos que se desencadearam no Brasil nestes últimos anos, em especial a partir das vésperas das Olímpiadas de 2013 e que se projetam até os dias atuais dada a instabilidade política e crise econômica vivida pelos brasileiros. 
A importância da pesquisa se revela atual e relevante dada a insegurança jurídica e pouco debate existente no Brasil a respeito da eventual responsabilidade civil decorrentes dos atos de piquetes, inclusive por parte de membro indeterminado ou mesmo dos piquetes que não guardam relação com os conflitos trabalhistas. $O$ estudo da jurisprudência norte-americana, assim, revela-se pertinente, já que seus precedentes podem ser utilizados como parâmetros persuasivos para eventuais decisões dos tribunais brasileiros.

Nesta pesquisa utilizamos o método dedutivo, a partir da análise das decisões dos tribunais norte-americanos, além da revisão da sua doutrina, optando-se pelo estudo na área da ciência dogmática do Direito.

\section{DO DEBATE AMERICANO SOBRE $O$ DIREITO AO PIQUETE E RESPONSABILIDADE DELE DECORRENTE}

Ainda que o berço maior do movimento trabalhista tenha sido a Europa, talvez não exista outro país na qual $\mathrm{o}$ direito ao piquete e a sua consequente responsabilidade civil tenha sido objeto de debate jurídico tão mais intenso e remotamente do que nos Estados Unidos. Para tanto basta citar que já em 1894 era publicado na The Yale Law Journal artigo doutrinário a respeito da possibilidade de se emitir ordem judicial (injunção) contra o piquete com objetivo trabalhista (BULLARD, 1894). Já na Harvard Law Review (vol. 9, n. 7), em 1896, era publicado outro artigo comentando a legislação inglesa do ano anterior, inclusive a que tratava dos direitos decorrentes dos movimentos trabalhistas (ALSTON, 1896). O mesmo pode ser dito de publicação da The American Law Register and Review, em 1896, na qual se debatia sobre uma decisão da Justiça inglesa a respeito de piquete (STEWART, 1896, p. 460-461).

Mais importante, no entanto, foi uma nota anônima (creditando-se aos editores) lançada na Harvard Law Review (vol. 10, n. 5), ainda em 1896, comentando decisão da Corte Suprema de Massachusetts a respeito da ordem judicial para impedir a continuidade de um piquete (HARVARD, 1896, p. 301-302). A partir dessa decisão (ESTADOS UNIDOS, 1896) e dos seus comentários, novos e sucessivos artigos 
doutrinários se sucederam em diversas revistas norte-americanas debatendo esta decisão e outras similares, a exemplo dos trabalhos publicados nos periódicos The Virginia Law Register (PETERKIN, 1897, p. 556, e PATTESON, 1898, p. 632), The American Law Register (LEWIS, 1898, p. 4) (HUFFCUT, 1898, p. 283), The Yale Law Journal (YALE, 1900, p. 402) e Harvard Law Review (HARVARD, 1900, p. 219).

$\mathrm{Na}$ decisão da Suprema Corte de Massachusetts foi analisado um caso no qual um grupo de trabalhadores colocou na porta de uma empresa uma "patrulha" (com dois homens) para evitar que outras pessoas pudessem ser contratadas e de modo interferir nos negócios do empregador até que este cedese nas negociações salariais. Com essa conduta, buscavam intimidar outras pessoas em seus negócios com o empregador. Alegou-se que a "patrulha" se utilizava de persuasão, pressão social e ameaças de ferimentos pessoais ou dano ao patrimônio das pessoas empregadas pela empresa ou que fossem procurar emprego, além dos seus clientes. Na oportunidade, por maioria, decidiu-se pela emissão de uma injunção (ESTADOS UNIDOS, 1896). Em votos divergentes, dois julgadores ressaltaram que descabia a ordem judicial se "(1) a patrulha fosse dissociada de ameaças de ferimento físico a pessoa ou propriedade, e (2) não houvesse qualquer tentativa combinada de interferir no negócio, embora sem tais ameaças e independentemente dos meios empregados" (ESTADOS UNIDOS, 1896, p. 92).

Os debates nos Estados Unidos se sucederam ao longo dos primeiros anos do Século 20, alcançando-se os tribunais em face dos litígios trabalhistas ocorrentes. Já em 1930, por exemplo, contava-se 118 decisões de diversos tribunais norteamericano concedendo ou não injunções contra atos de piquete (FRANKFURTER, 1963, p. 231-257). A resistência aos atos de piquetes, por sua vez, era patente à época, chegando a Suprema Corte, em 1921, ao apreciar a aplicação da Clayton Act (ESTADOS UNIDOS, 1914), admitir que, de fato, esta lei se referia ao "sinistro" nome "picketing" para tê-lo como legal (ESTADOS UNIDOS, 1921, p. 207).

No ponto objeto deste trabalho, no entanto, o debate relativo ao direito ao piquete e a responsabilidade civil dele decorrente alcançou a Corte Suprema dos Estados Unidos ao final da década de 30 do Século passado, prologando-se com a sedimentação da jurisprudência no ano de 2011. Aqui, então, cabe comentar as decisões mais significativas. São os casos Thornhill v. Alabama (1940), Milk Wagon 
Drivers Union of Chicago, Local 753 et al. v. Meadowmoor Dairies, Inc. (1941), Brotherhood of Carpenters v. United States (1947), United Mine Workers v. Gibbs (1966), Carbon Fuel Co. v. Mine Workers (1979) e Snyder v. Phelps (2011).

\section{O CASO THORNHILL V. ALABAMA (1940)}

É preciso destacar que ao longo dos primeiros 30 anos do Século $X X$, a Suprema Corte americana concluiu pela inconstitucionalidade de lei federal que tratava de direitos trabalhistas. Assim é que, no caso Carter v. Carter Coal Co. (1936), por exemplo, concluiu que:

[...] a relação entre empregador e empregado é uma relação local e consequentemente fora da jurisdição Federal... a relação entre empregador e empregado, no direito comum, é uma das relações domésticas... os poderes que o governbo geral pode exercer são apenas aqueles enumerados especificamente na Constituição, e aqueles poderes implícitos que foram necessários e apropriados para o uso efetivo dos poderes enumerados. (ESTADOS UNIDOS, 1936, p. 291. tradução nossa).

Nesta mesma decisão, chegou-se a afirmar que as:

[...] lutas entre o empregador e os empregados em matéria de salários, condições de trabalho, direito de negociação coletiva, etc., e as consequentes greves, cortes e irregularidades de produção e efeito sobre os preços, por maiores que sejam esses males, somente pode afetar o comércio interestadual de forma secundária e indireta. São questões locais sobre os quais o governo federal não tem competência legislativa" (ESTADOS UNIDOS, 1936, p. 242, tradução nossa).

Foi neste contexto que se esperava que a Corte Suprema acabasse por considerar inconstitucional a Lei Norris-La Guardia de 1932, que estabelecia regras sobre a concessão de injunções em matéria relacionada aos direitos do trabalho (ESTADOS UNIDOS, 1932). Já em 1935, ainda na onda das políticas introduzidas pelo New Deal, foi aprovada a National Labor Relations Act, esta também conhecida como Lei Wagner (ESTADOS UNIDOS, 1935), que, entre outras disposições, disciplinava a negociação coletiva, a sindicalização, o direito de greve, etc. Surpreendentemente, no entanto, muito mais por pressão política e popular 
decorrente da implantação do programa de recuperação econômica do New Deal (PETERSON, 1953, p. 85), a Suprema Corte, no caso NLRB v. Jones \& Laughlin Steel Corp., em 1937 (ESTADOS UNIDOS, 1937), revertendo sua jurisprudência, considerou constitucional a National Labor Relations Act. Com esa decisão a Suprema Corte abriu suas portas para, então, passar a apreciar a legislação federal relativa aos conflitos trabalhistas.

Assim é que em 1940 chegou à Corte Suprema americana um apelo na qual se questionava uma lei do Estado do Alabama na qual se criminalizava o fato de perambular (to loiter) ou fazer piquetes:

[...] nas instalações ou lugar de negócios de qualquer pessoa, empresa, corporação ou associação de pessoas, implicadas em um negócio lícito, com o propósito ou com a intenção de influir ou induzir outras pessoas para que não comerciem, comprem, vendam, tenham tratos comerciais ou sejam empregadas, por ditas pessoas, empresa, corporação ou associação (ESTADOS UNIDOS, 1940b, p. 91-92, tradução nossa).

Esta mesma lei proibia a divulgação de fatos relativos a uma disputa trabalhista, seja por sinal impresso, por folheto, por conversas (boca-a-boca) ou de outra forma, "na vizinhança do negócio envolvido", sendo impertinente o "número de pessoas envolvidas em tal atividade, o caráter pacífico de sua conduta, a natureza da disputa ou a precisão ou restrição do idioma utilizado na divulgação da informação" (ESTADOS UNIDOS, 1940b, p. 88, tradução nossa).

Apreciando a questão à luz do texto da Primeira (ESTADOS UNIDOS, 1791) e da Décima Quarta (ESTADOS UNIDOS, 1868) Emendas da Constituição americana, a Suprema Corte considerou inconstitucional a lei do Alabama por violar a liberdade de expressão e a proteção das pessoas em seus direitos e liberdades contra qualquer intromissão indevida do Estado. É certo, porém, que a constitucionalidade não poderia ser apreciada à luz da National Labor Relations Act (ESTADOS UNIDOS, 1935) ou mesmo da Clayton Act (ESTADOS UNIDOS, 1914), que também prevê regras relacionadas às manifestações de boicote ou protestos, já que estas leis são federais de natureza ordinária.

$\mathrm{Na}$ oportunidade, então, pelo voto de oito ministros, com uma divergência, decidiu-se que: 
[...] não há nenhum perigo claro e presente de destruição da vida ou da propriedade, ou a invasão do direito à privacidade, ou violação da paz, que possa a partir da conduta de qualquer um que se aproxima das instalações de uma empresa e faz publicidade de fatos relativos a um conflito trabalhista desta última" (ESTADOS UNIDOS, 1940b, p. 105).

À luz da liberdade de expressão, então, conclui-se que não se poderia impedir que trabalhadores pudessem agir de modo a tentar influir ou induzir outras pessoas para que não comercializassem com uma empresa ou mesmo que pudessem divulgar fatos relacionados aos conflitos trabalhistas.

Em semelhante conclusão, no caso American Federation of Labor v. Swing (1941), a Suprema Corte também conclui que a garantia constitucional de liberdade de expressão é violada por lei ordinária que limita a realização de piquete pacífico por sindicatos em casos em que a controvérsia é entre o empregador e os seus próprios empregados (ESTADOS UNIDOS, 1941a, p. 312). Esse precedente foi reiterado, ainda, no caso Bakery \& Pastry Drivers \& Helpers Local 802 of the International Brotherhood of Teamsters et al. v. Wohl et al. (ESTADOS UNIDOS, 1942a).

Contudo, já na decisão do caso Carpenters \& Joiners v. Ritter's Cafe (1942), a Suprema Corte teve como válida a injunção emitida contra a prática de piquete (protesto), ainda que feito por trabalhadores, junto a um restaurante cujo proprietário estava construindo um edifício no qual não foram contratados empregados sindicalizados. No caso, os trabalhadores da construção civil faziam piquete junto ao restaurante. Considerou-se, neste caso, que seria abusivo o piquete diante de uma empresa (no caso o restaurante) que não seria parte na controvérsia trabalhista, no caso a construção de outro prédio envolvendo o proprietário daquela primeira (ESTADOS UNIDOS, 1942b)

\section{O CASO MILK WAGON DRIVERS UNION OF CHICAGO, LOCAL 753 ET AL. V. MEADOWMOOR DAIRIES, INC. (1941)}

A decisão firmada no caso Thornhill v. Alabama (concluída em abril de 1940) foi completada, pouco menos de um ano depois (em fevereiro de 1941), com o 
precedente adotado no caso Milk Wagon Drivers Union of Chicago, Local 753 et al. v. Meadowmoor Dairies, Inc. (ESTADOS UNIDOS, 1941c).

No caso, a Suprema Corte esteve diante de um recurso contra decisão que concedeu uma injunção para tentar impedir a realização de atos de violência durante a realização de piquetes, respeitando-se, porém, a manifestação pacífica. No caso, discutia-se se os tribunais poderiam interferir em atos de piquetes massivos violentos, nos quais, dentre outros atos, foram lançadas bombas fétidas contra estabelecimentos, caminhões foram danificados, pessoas foram feridas, armazéns incendiados, etc.

Importante, porém, ressaltar que coube ao Juiz Felix Frankfurter a redação do teor da decisão, adotada pela maioria de cinco contra três votos divergentes. Frankfurter era, já antes de sua nomeação para a Corte Suprema em 1938, considerado um dos mais prestigiados professores de direito do trabalho norteamericano, tendo atuado na Faculdade de Direito de Harvard, sendo coautor de uma obra sobre os interditos (injunções) nas relações de trabalho, editada inicialmente em 1930 (FRANKFURTER, 1963). Esta obra influenciou a promulgação da denominada Lei Norris-La Guardia (também conhecido como o Bill Anti-Injunction), através da qual se proibiu de os tribunais emitir injunções contra conflitos trabalhistas não-violentos (ESTADOS UNIDOS, 1932), reforçando o que em parte já estava previsto na Clayton Act, em seu § 20 (ESTADOS UNIDOS, 1914)

No caso Milk Wagon Drivers Union of Chicago, Local 753 et al. v. Meadowmoor Dairies, Inc. a Suprema Corte fez a distinção em relação ao decidido no caso Thornhill v. Alabama, pois neste não se estava diante de um conflito com uso de violência. No novo caso, conclui-se que se respeitou a Constituição quando se garantiu o piquete não violento, inclusive enquanto meio de comunicação dos trabalhadores (ESTADOS UNIDOS, 1941c, p. 293), até porque os atos de violência não poderiam justificar a vedação à liberdade de expressão. Decidiu-se, ainda, que, quando diante da violência, as portas do Judiciário estariam sempre abertas para impedir que a agressão injusta continuasse a ocorrer (ESTADOS UNIDOS, 1941c, p. 298).

Contudo, o que de destaque se extrai de relevante dessa decisão foi a conclusão quanto a responsabilidade civil dos sindicatos. No caso, os sindicalistas 
afirmaram que os atos de violência foram praticados por terceiros, sem interferência da entidade sindical. A Suprema Corte, porém, não se convencendo destas alegações, pois "os juízes não precisam ser tão ingênuos sobre a realidade dos conflitos industriais" (ESTADOS UNIDOS, 1941c, p. 292), acabou por decidir que "a associação sindical, assim como um empresário, pode ser responsabilizada por atos que não tenham sido expressamente autorizados ou que não podem ser atribuídos pela aplicação estrita das regras de responsabilidade superior" (ESTADOS UNIDOS, 1941c, p. 295).

Com essa conclusão, a Corte Suprema reconhecia a responsabilidade extracontratual do organizador do evento (dos piquetes), ainda que não fosse conhecido o ofensor.

\section{O CASO BROTHERHOOD OF CARPENTERS V. UNITED STATES (1947)}

Seis anos depois, a Suprema Corte americana se defrontou com um novo caso. Trata-se do conflito Brotherhood of Carpenters v. United States (1947) (ESTADOS UNIDOS, 1947b). Neste caso, o juiz Frankfurter ficou ao lado da minoria de três em face dos cinco votos que compuseram a maioria.

No caso, empresas, sindicatos e seus associados, um grupo de sindicatos sem personalidade jurídica e seus associados foram indiciados por conspiração ante a acusação de que ilegalmente combinaram e conspiraram juntos, com sucesso, para monopolizar indevidamente uma parte do comércio interestadual com o objetivo de restringir que os fabricantes de outro Estado fizessem o transporte e venda de mercadorias em uma determinada área. Essa conspiração visava elevar os preços das commodities e, para tanto, foi firmado um contrato estabelecendo uma escala salarial para os membros dos sindicatos, combinada com uma cláusula restritiva na qual nenhum outro material similar seria comprado pelos trabalhadores ou realizado qualquer serviço (trabalho) em favor das empresas de fora do Estado.

Ao tratar da responsabilidade das entidades sindicais, entretanto, a Suprema Corte lembrou (ao contrário do que ocorrera na decisão anterior) que ainda estava em 
vigor a Lei Norris-La Guardia (desde 1932), a qual, em seu $\S 6$ (do 29 U.S. Code Chapter 6), dispõe que:

\begin{abstract}
Nenhum dirigente ou filiado de qualquer associação ou organização, e nenhuma associação ou organização participante ou interessado em uma disputa trabalhista, será considerada responsável operante qualquer tribunal dos Estados Unidos pelo atos ilícitos praticados individualmente por diretores, filiados ou representantes, salvo mediante prova clara da participação real em tais atos, ou autorização concreta para os mesmos, ou quando diante de atos de ratificação após o conhecimento real dos mesmos" (ESTADOS UNIDOS, 1932, p. 71, tradução nossa).
\end{abstract}

Nesta decisão, ainda, firmou-se o entendimento de que:

4. O objetivo e o efeito do $\S 6$ da Lei Norris-La Guardia é resguardar organizações, sejam de trabalho ou o capital, e os membros dessas organizações, de responsabilidade por danos ou imputações de culpa por atos ilegais realizados em alguma disputa trabalhista coletiva ou individual ou por membros da organização sem prova clara de que a organização ou membro tenha responsabilidade pela infração com a qual participou, deu autorização prévia, ou que tais atos foram ratificados após o conhecimento real da sua perpetração (ESTADOS UNIDOS, 1947b, p. 396).

Decidiu-se, ainda que "5. A palavra "organização", conforme usado na lei, não está restrito a entidades sem personalidade jurídica, mas abrange genericamente todos que participam em organizações em disputas trabalhistas, incluindo corporações" e que:

7. Conforme utilizado no $\S 6$, "autorização" significa algo diferente de atos criminosos para o reconhecimento da responsabilidade corporativa por atos de dirigentes e filiados no curso ou âmbito do emprego"... "ainda que tais diretores ou membros estejam agindo no âmbito de sua competência geral"..., "salvo mediante prova clara de que para determinado ato, ou que age geralmente nesse tipo e qualidade, ou fora expressamente autorizado, ou necessariamente seguiu uma ordem concedida, pela associação ou membro não participante, ou procurou ser autorizado ou foi posteriormente ratificado por tal associação, organização ou membro, depois do conhecimento real de sua ocorrência (ESTADOS UNIDOS, 1947b, p. 396).

Assim, com essa nova decisão, a Suprema Corte ressaltou que não se poderia imputar a responsabilidade extracontratual ao organizador dos eventos decorrentes de conflitos trabalhistas por ato não expressamente autorizado (com "prova clara") pela entidade sindical. 


\section{O CASO UNITED MINE WORKERS V. GIBBS (1966)}

Quase vinte anos depois, a Suprema Corte americana voltou a se defrontar com a mesma questão relacionada ao direito de manifestação pública (piquetes) e sua responsabilidade.

Neste interregno, na verdade ainda em 1947, logo após a decisão anteriormente comentada, foi promulgada a denominada Lei Taft-Hartley (ESTADOS UNIDOS, 1947a), que introduziu mudanças na National Labor Relations Act (ESTADOS UNIDOS, 1935). Esta nova lei foi sancionada pelo Congresso, já agora majoritariamente republicano, após derrubar o veto do Presidente Truman (PETERSON, 1953, p. 94). Ela significou uma reação conservadora aos direitos assegurados na Lei Norris-La Guardia e na Lei Wagner. Ela chegou a ser denominada "lei de escravidão de trabalho", sendo acusada de ser um "ataque vindicativo contra os sindicatos" (PETERSON, 1953, p. 94).

De importante, a destacar é que este novo ato legislativo introduziu o conceito de piquete primário e secundário. Primário seria o piquete praticado pelo trabalhador em face do seu empregador; secundário seria o piquete de solidariedade, ou seja, dirigido contra ato de empresa distinta do empregador dos trabalhadores que participam do piquete. Esta segunda espécie de piquete, assim, passou a ser considerado como ilícito. Contudo, em relação ao primário se estabeleceu o princípio de que nada se interpretará como ilegal, salvo quando por outro modo seja ilegal, qualquer greve ou piquete primário (Art. 8, alínea "b", item 4, inciso ii, seção B).

E mais. Com essa nova lei, em reação ao decidido pela Suprema Corte anteriormente, ficou estabelecido claramente a responsabilidade das entidades sindicais pelos atos de seus agentes, sejam dirigentes ou filiados (art. 301), inclusive por atos de boicote (art. 303).

Foi diante desse novo quadro normativo e com uma composição renovada que a Suprema Corte americana, em 1966, apreciou o caso United Mine Workers v. Gibbs.

Nesta ação atuou de um lado o sindicato americano dos trabalhadores mineiros. Importante, porém, ressaltar que, conforme sistema de organização sindical no Brasil, esse sindicato americano pode ser considerado uma federação ou 
confederação de entidades sindicais. Isso porque ele reúne o que se denomina de "district union", isto é, entidade sindical de atuação em menor espaço territorial, que seriam os nossos sindicatos ou federações. A United Mine Workers, portanto, seria, para o direito brasileiro, uma federação ou uma confederação sindical.

Do outro lado da demanda judicial participou o senhor Gibbs. Este senhor processou a entidade sindical nacional dos mineiros ante a acusação de que, diante de um movimento grevista, aquela impediu a abertura de uma mina, além de ameaçálo e agredi-lo. O senhor Gibbs, então, apresentou demanda pedindo o reconhecimento da responsabilidade extracontratual com base na Lei Taft-Hartley, sem demandar, todavia, a entidade sindical local.

A Corte Suprema norte-americana, por sua vez, dando uma nova interpretação às leis vigentes, ao apreciar esse novo caso afirmou que a Lei TaftHartley não havia derrogado expressamente 0 § 6 da Lei Norris-La Guardia, daí porque seria necessária uma "prova clara" de que a entidade sindical havia autorizado a prática dos atos ilícitos.

Decidiu-se, assim, que:

Enquanto o National Labor Relations Act prevê expressamente que, para efeitos desse ato, incluindo o art. 303, a responsabilidade do sindicato por atos de seus membros e filiados deve ser medida pelos padrões das autorizações comuns, ao invés o $\S 6$ da norma mais rigorosa exige 'prova clara (ESTADOS UNIDOS, 1966, p. 716).

E por "prova clara" se entende a "prova inequívoca e convincente" (ESTADOS UNIDOS, 1966, p. 716).

Assim, a Suprema Corte, considerando, ainda, o fato de que o sindicato nacional estava distante dos atos praticados pela entidade local, de modo a afastar qualquer evidência que teria aprovado ou ratificado os atos violentos, acabou por afastar qualquer responsabilidade do demandado.

Manteve, assim, a Suprema Corte o entendimento de que não se pode imputar a outrem a responsabilidade por atos não claramente autorizados ou ratificados. Fez incidir, no caso, diante da falta de prova clara, a regra da Lei Norris-La Guardia, em detrimento do disposto na Lei Taft-Hartley. 


\section{O CASO CARBON FUEL CO. V. MINE WORKERS (1979)}

Treze anos depois, nova demanda chega à Suprema Corte americana. Só que desta vez foi demandado a entidade sindical nacional ao lado da sua subdivisão regional e mais três sindicatos locais.

No caso, debatia-se a responsabilidade por atos decorrentes de uma greve "selvagem", isto é, sem o devido respeito aos procedimentos para sua deflagração e na vigência de um acordo coletivo, com violação à cláusula de paz.

A Suprema Corte reforçou seu entendimento afastando a responsabilidade da entidade regional e nacional por atos eventualmente praticados pelos sindicatos locais diante da falta de prova clara de suas participações. Já quanto a análise da responsabilidade civil dos sindicatos locais ficou estabelecido novo precedente, ampliando seu o âmbito de aplicação (da responsabilidade civil), ao se decidir que a Lei Taft-Hartley previa que o direito civil relativo ao mandato se aplicaria para determinar se uma pessoa estaria ou não atuando como representante de outra (ESTADOS UNIDOS, 1979, p. 216). Logo, a entidade sindical poderia ser responsabilizada pelo direito comum relativo ao mandato. Com isso, voltaria a se aplicar aos sindicatos as regras de direito comum, retornando-se a uma situação anterior à promulgação da Lei Norris-La Guardia de 1932.

Sufragou-se, desse modo, a teoria da responsabilidade superior (respondeat superior), isto é, a responsabilidade daquele que estaria agindo como proponente (superior) em face do preposto, ainda que em mandato aparente (apparent authority) ou mandato tácito (ESTADOS UNIDOS, 1979, p. 217).

Entendeu-se que quando o sindicato age enquanto tal deve ser responsabilizado pelos atos de seus filiados e dirigentes quando estes atuam numa ação coletiva. Isso porque se argumentou que é óbvio que as pessoas não atuam coletivamente sem uma liderança. Logo, mesmo quando diante de atos de pessoas não identificadas, se imputaria ao sindicato a responsabilidade pelos atos dos seus dirigentes, dos grevistas e demais participantes do piquete.

É importante, porém, sempre destacar que se concluiu que o movimento operário foi tido como ilegal, já que deflagrado com desrespeito aos procedimentos exigidos e na vigência de um acordo coletivo. 
Com essa decisão, portanto, a Suprema Corte passou a sustentar o entendimento de que a entidade sindical responde pelos atos ilegais de seus dirigentes, filiados e demais prepostos que, sob sua liderança, praticam atos ilegais ou abusivos, ainda que $o$ ato ilícito tenha sido praticado por pessoa indeterminada (não identificada).

\section{O CASO SNYDER V. PHELPS (2011)}

Por fim temos o caso Snyder v. Phelps (2011) decidido em 2011 (ESTADOS UNIDOS, 2011)

Aqui não se trata de uma questão trabalhista. No caso, discutiu-se a responsabilidade de uma entidade por atos de piquete, ou, na linguagem de nossa cultura jurídica, de atos de protesto.

No caso, uma entidade religiosa denominada Igreja Batista de Westboro, que tem por preceito que "crer que Deus odeia e castiga os Estados Unidos por sua tolerância com a homossexualidade, particularmente no exército americano" (ESTADOS UNIDOS, 2011, p. 448), comandou um piquete (protesto) durante o funeral do marinheiro Snyder, que morreu em combate no Iraque.

Os pais do soldado morto ajuizaram, então, uma demanda contra a dita Igreja exigindo indenização por danos e prejuízos. Interessante destacar que ao lado dos autores ingressaram no feito, na qualidade de amicus curiae, o próprio Estados Unidos e todos os cinquenta Estados federados e mais o Distrito de Columbia.

A Suprema Corte, por sua vez, em votação majoritária de oito membros, com a divergência de apenas um, conclui que descaberia a condenação em indenização, já que o piquete se desenvolveu sem qualquer ato de violência, desordem, profanação, agressão ou obscenidade (ESTADOS UNIDOS, 2011). Logo, no caso, caberia ser respeitado a liberdade de expressão de modo a não se ter como ilícita a conduta dos manifestantes.

Com essa decisão, portanto, a Suprema Corte reafirmou seu precedente que a liberdade de expressão agasalha as manifestações públicas nas quais alguém 
promove um movimento (piquete, bloqueio ou protesto), desde que não use de violência contra outras pessoas e o patrimônio alheio.

É certo, porém, que a Corte americana passou ao largo da responsabilidade pelos danos morais decorrentes do ato em si, realizado durante um funeral e em face de uma conduta discriminatória aos homossexuais.

De qualquer forma, vale citar que, anteriormente, em 1988, no caso Frisby v. Schultz, a Suprema Corte, a despeito da cláusula de liberdade de expressão, teve como constitucional uma lei de Wisconsin que proibia piquetes (manifestações públicas) em áreas residenciais ou nas portas de residências a pretextos de assegurar "uma sensação de bem-estar, tranquilidade e privacidade" (ESTADOS UNIDOS, 1988, p. 474).

Da mesma forma, em 1994, a Suprema Corte, no caso Madsen v. Women's Health Center, Inc, também teve como constitucional a ordem judicial que restringia, inclusive delimitando uma área de segurança, o piquete (protesto) levado a cabo junto a uma clínica que realizava aborto (ESTADOS UNIDOS, 1994). Neste caso, também se teve como constitucional a restrição à liberdade de expressão, já que, no caso, de qualquer forma, ela não foi banida, mas apenas limitada o seu exercício em uma determinada área distante da clínica.

\section{CONCLUSÃO}

Em apertada síntese podemos, então, concluir que a Suprema Corte dos Estados Unidos, ao longo de pouco mais de setenta anos (entre 1940 e 2011), alternou seu entendimento quanto a responsabilidade civil dos sindicatos em face dos atos praticados em piquetes e greve.

É certo que, desde a promulgação da Lei Norris-La Guardia, a Suprema Corte passou a reconhecer a legalidade da greve e dos piquetes lícitos enquanto manifestação da liberdade de expressão. Contudo, num primeiro momento, foi reconhecida a possibilidade de a entidade sindical responder pelos atos ilícitos de seus dirigentes, filiados e demais participantes dos piquetes, por força da 
responsabilidade decorrente da aplicação da doutrina do mandato (caso Milk Wagon Drivers Union of Chicago, Local 753 et al. v. Meadowmoor Dairies, Inc, 1941).

Posteriormente, decidiu-se que a entidade sindical não responderia extracontratualmente em decorrência de atos ilícitos de seus dirigentes, filiados e demais participantes dos piquetes (caso Brotherhood of Carpenters v. United States, 1947). Em seguida, porém, recuando em parte, passou a entender que a entidade sindical responderia pelos atos de seus dirigentes, filiados e demais participantes do movimento grevista e dos piquetes, mas desde que ficasse claramente comprovado que o sindicato tenha autorizado ou ratificados os atos ilegais (caso United Mine Workers v. Gibbs, 1966).

Recuando nesta última posição, no entanto, em precedente atualmente predominante, a Suprema Corte dos Estados Unidos passou a entender, desde 1979, que a entidade sindical responde pelos atos de seus dirigentes, filiados e demais participantes das greve e piquetes por força da aplicação da responsabilidade civil decorrente dos atos de mandato, ainda que aparente ou tácito, inclusive em face de ato praticado por pessoa indeterminada ou não identificada (caso Carbon Fuel Co. v. Mine Workers).

Por fim, em 2011, foi reiterada a doutrina de que não se pode imputar a qualquer manifestante ou entidade a responsabilidade por atos que decorram do exercício da liberdade de expressão, seja em atos realizados em piquetes decorrentes de conflitos trabalhistas ou não (caso Snyder v. Phelps).

\section{REFERÊNCIAS}

ALSTON, G. Rowland. The English Statutes of 1895. Harvard Law Review, Vol. 9, n. 7 (Feb. 25, 1896), p. 439-446. The Harvard Law Review Association. 1896. Disponível em: http://www.jstor.org/stable/1322209. Acesso em: 15 jun. 2017.

BULLARD, Herbert S. The injunction as a remedy for the boycott. The Yale Law Journal, Vol. 3, n. 6 (Jun. 1894), p. 211-217. The Yale Law Journal Company, Inc. 1894. Disponível em: http://www.jstor.org/stable/783023. Acesso em: 16 jun. 2017.

ESTADOS UNIDOS DA AMÉRICA. The First Amendment (Amendment I) to the United States Constitution. Freedom of expression and religion. 1791. Disponível em: 
https://en.wikipedia.org/wiki/United_States_Bill_of_Rights\#First_Amendment. Acesso em 15 jun. 2017.

. The Fourteenth Amendment (Amendment XIV) to the United States Constitution. Rights Guaranteed: Privileges and Immunities of Citizenship, Due Process, and Equal Protection. 1868. Disponível em: http://constitutionus.com/. Acesso em 15 jun. 2017.

Corte Suprema de Massachusetts. Frederick O. Vegelahn v. George M.

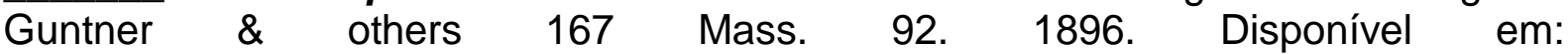
http://masscases.com/cases/sjc/167/167mass92.html. Acesso em: 15 jun. 2017.

Public Law n. 212. An Act to supplement existing laws against unlawful restraints. 63rd United States Congress. 1914. Disponível em: http://www.legisworks.org/congress/63/publaw-212.pdf. Acesso em: 18 jun. 2017.

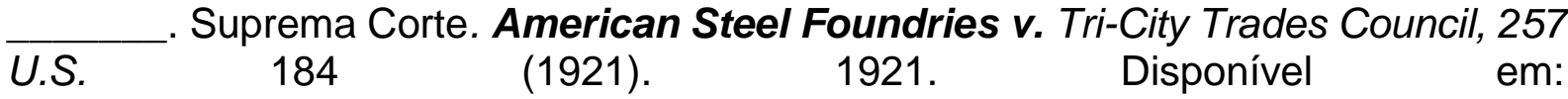
https://supreme.justia.com/cases/federal/us/257/184/case.html. Acesso em: 18 jun. 2017.

Public Law n. 65. An Act to amend the Judicial Code and to define and limit the jurisdiction of courts sitting in equity, and for other purposes. 72rd United States Congress. 1932. Disponível em: http://legisworks.org/sal/47/stats/STATUTE-47Pg70.pdf. Acesso em: 15 jun. 2017.

National Labor Relations Act. Act of July 5, 1935, Public Law 74-198, An Act to diminish the causes of labor disputes burdening or obstructing interstate and foreign commerce, to create a National Labor Relations Board, and for other purposes. 1935. Disponível em: https://www.nlrb.gov/resources/national-labor-relations-act. Acesso em: 15 jun. 2017.

Suprema Corte. Carter v. Carter Coal Co., 298 U.S. 238 (1936). 1936. Disponível em: https://supreme.justia.com/cases/federal/us/298/238/case.html. Acesso em: 18 jun. 2017.

. NLRB v. Jones \& Laughlin Steel Corp., 301 U.S. 1 (1937). 1937. Disponível em: https://supreme.justia.com/cases/federal/us/301/1/case.html. Acesso em: 18 jun. 2017.

Carlson v. California, 310 U.S. 106 (1940). 1940a. Disponível em: Https://supreme.justia.com/cases/federal/us/310/106/case.html. Acesso em: 15 jun. 2017.

Thornhill v. Alabama, 310 U.S. 88 (1940). 1940b. Disponível em: https://supreme.justia.com/cases/federal/us/310/88/case.html. Acesso em: 15 jun. 2017. 
1941a.

American Federation of Labor v. Swing, 312 U.S. 321 (1941).

https://supreme.justia.com/cases/federal/us/312/321/case.html. Acesso em: 15 jun. 2017.
(1941).
Milk Wagon Drivers v. Meadowmoor Dairies, Inc., 312 U.S. 287 1941c. Disponivel em: https://supreme.justia.com/cases/federal/us/312/287/case.html. Acesso em: 15 jun. 2017.

Bakery Drivers Local v. Wohl, 315 U.S. 769 (1942). 1942a. Disponível em: https://supreme.justia.com/cases/federal/us/315/769/case.html. Acesso em: 15 jun. 2017.

. Carpenters \& Joiners v. Ritter's Cafe, 315 U.S. 722 (1942).

1942b. Disponível

em: https://supreme.justia.com/cases/federal/us/315/722/case.html. Acesso em: 15 jun. 2017.

Labor Management Relations Act. Public Law 101. An Act to amend the National Labor Relations Act, to provide additional facilities for the mediation of labor disputes affecting commerce, to equalize legal responsibilities of labor organizations and employers, and for other purposes. 80th United States Congress. 1947a. Disponível em: http://www.legisworks.org/congress/80/publaw-101.pdf. Acesso em: 15 jun. 2017.
(1947). 1947b. Disponível em: https://supreme.justia.com/cases/federal/us/330/395/case.html. Acesso em: 15 jun. 2017.

Public Law 86-257. An Act to provide for the reporting and disclosure of certain financial transactions and administrative practices of labor organizations and employers, to prevent abuses in the administration of trusteeships by labor organizations, to provide standards with respect to the election of officers of labor organizations, and for other purposes. 86th United States Congress. 1959. Disponível em: $\quad$ https://www.gpo.gov/fdsys/pkg/STATUTE-73/pdf/STATUTE-73-Pg519.pdf. Acesso em: 15 jun. 2017.

. Suprema Corte. United Mine Workers v. Gibbs, 383 U.S. 715 (1966). 1966. Disponível em: https://supreme.justia.com/cases/federal/us/383/715/case.html. Acesso em: 15 jun. 2017.

Public Law 93-360. An Act To amend the National Labor Relations Act to extend its coverage and protection to employees of nonprofit hospitals, and for other purposes. 93rd United States Congress. 1974. Disponível em: 
https://www.gpo.gov/fdsys/pkg/STATUTE-88/pdf/STATUTE-88-Pg395.pdf. Acesso em: 15 jun. 2017.

. Suprema Corte. Carbon Fuel Co. v. Mine Workers, 444 U.S. 212 (1979). 1979. Disponível em: https://supreme.justia.com/cases/federal/us/444/212/case.html. Acesso em: 15 jun. 2017.

Frisby v. Schultz, 487 U.S. 474 (1988). 1988. Disponível em: https://supreme.justia.com/cases/federal/us/487/474/case.html. Acesso em: 15 jun. 2017.

Madsen v. Women's Health Center, Inc. 512 U.S. 753 (1994). 1994. Disponível em: https://supreme.justia.com/cases/federal/us/512/753/. Acesso em: 15 jun. 2017.

Snyder v. Phelps 562 U.S. 443 (2011). 2011. Disponível em: https://supreme.justia.com/cases/federal/us/562/09-751/. Acesso em: 15 jun. 2017.

Corte de Apelação. Ninth Circuit. National Labor Relations Board, Petitioner-Appellee, v. International Longshore and Warehouse Union, Locals 21 and 4. 2013. Disponível em: http://caselaw.findlaw.com/us-9th-circuit/1637623.html. Acesso em: 15 jun. 2017.

FRANKFURTER, Felix. GREENE, Nathan. The labor injunction. Gloucester (Massachusetts): Peter Smith, 1963. 343p. s/ISBN. ASIN B000858Y9G.

HARVARD LAW REVIEW. Notes. "Picketing"- injunctions against strikers. Harvard Law Review, Vol. 10, n. 5 (Dec. 26, 1896), p. 301-302. The Harvard Law Review Association. 1896. Disponível em: http://www.jstor.org/stable/1321589. Acesso em: 19 jan. 2017.

. Notes. The legality of strikes. Harvard Law Review, Vol. 14, n. 3 (Nov., 1900), p. 219-22. The Harvard Law Review Association. 1900. Disponível em: http://www.jstor.org/stable/1323903. Acesso em: 15]6 jun. 2017.

HUFFCUT, Ernest Wilson. Interference with contract relations. The American Law Register (1898-1907), Vol. 46, n. 5, Volume 37 New Series (May,1898), p. 273-294. The University of Pennsylvania Law Review. 1898. Disponível em: http://www.jstor.org/stable/3306344. Acesso em: 16 jun. 2017.

LEWIS, William Draper. Strikes and courts of equity. The American Law Register (1898-1907), Vol. 46, n. 1, Volume 37 New Series (Jan., 1898), p. 1-12. The University of Pennsylvania Law Review. 1898. Disponível em: http://www.jstor.org/stable/3306808. Acesso em: 16 jun. 2017. 
PATTESON, S. S, P. Government by injunction. The Virginia Law Register, Vol. 3, n. 9 (Jan., 1898), p. 625-635. Virginia Law Review. 1898. Disponível em: http://www.jstor.org/stable/1099192. Acesso em: 16 jun. 2017.

PETERKIN, Wm. G. Government by injunction. The Virginia Law Register, Vol. 3, n. 8 (Dec., 1897), p. 549-563. Virginia Law Review. 1897. Disponível em: http://www.jstor.org/stable/1097724. Acesso em: 16 jun. 2017.

PETERSON, Florence. Sindicatos operários norte-americanos. Trad. Evaristo de Moraes Filho. Rio de Janeiro: Agir, 1953. 332p. s/ISBN.

STEWARD, Ardemus. Progress of the law. As Marked by decisions selected from the advance reports for june. The American Law Register and Review, Vol. 44, n. 7, Volume 35 New Series (Jul.1896), p. 444-463. The University of Pennsylvania Law Review. 1896. Disponível em: http://www.jstor.org/stable/3305601. Acesso em: 16 jun. 2017.

YALE LAW JOURNAL. Strike. Injunction. Combinations of workmen. Picketing. Equity jurisdiction. CumberlandGlass Mfg. Co. v. Glass Bottle Blowers' Assn. et al. 46 Atl. 208. The Yale Law Journal, Vol. 9, n. 9 (Jul., 1900), p. 402. The Yale Law Journal Company, Inc. 1900. Disponível em: http://www.jstor.org/stable/782625. Acesso em: 16 jun. 2017. 